\title{
The value of multiple earthquake missions: the EEFIT L'Aquila Earthquake experience
}

\author{
T. Rossetto - D. D'Ayala - F. Gori · R. Persio - J. Han • V. Novelli • \\ S. M. Wilkinson - D. Alexander • M. Hill - S. Stephens · S. Kontoe • \\ G. Elia · E. Verrucci · A. Vicini · W. Shelley · R. Foulser-Piggott
}

Received: 28 October 2013 / Accepted: 5 January 2014 / Published online: 19 January 2014

(C) The Author(s) 2014. This article is published with open access at Springerlink.com

\begin{abstract}
In November 2012 EEFIT launched its first ever return mission to an earthquake affected site. The L'Aquila Earthquake site was chosen as this is a recent European event of interest to the UK and European earthquake engineering community. The main aims of this return mission were to document the earthquake recovery process and this paper presents an overview of the post-disaster emergency phase and transition to reconstruction in the Aquila area after the earthquake. It takes an earthquake engineering perspective, highlighting areas mainly of interest to the fields of structural/seismic engineering and reconstruction management. Within the paper, reference is made to published literature, but also to data collected in the field during the return mission that would not otherwise have been available.
\end{abstract}

T. Rossetto $(\varangle) \cdot$ D. D’Ayala · V. Novelli · E. Verrucci

EPICentre, Department of Civil and Environmental Engineering,

University College London, Gower Street, London WC1E 6BT, UK

e-mail: t.rossetto@ucl.ac.uk

F. Gori

Rijekaprojekt-Koning, Rijeka, Croatia

R. Persio

Arup Italia, Corso Italia, 13, Milan, Italy

J. Han · S. Kontoe

Department of Civil and Environmental Engineering, Imperial College London,

Exhibition Road, London SW7 2AZ, UK

S. M. Wilkinson · G. Elia

School of Civil Engineering and Geosciences, Newcastle University,

Newcastle NE1 7RU, UK

D. Alexander

Institute for Risk and Disaster Reduction, University College London,

Gower Street, London WC1E 6BT, UK

M. Hill

Risk Management Solutions Ltd., 30 Monument Street, London EC3R 8NB, UK 
The paper presents some specific observations and lessons learned from the L'Aquila return mission. However, in light of current international efforts in conducting return missions, the paper ends with some reflections on the value that return missions can provide to the field of earthquake engineering in general, based on the EEFIT L'Aquila experience.

Keywords L'Aquila Earthquake $\cdot$ Field survey $\cdot$ Strong ground motion $\cdot$ Building damage $\cdot$ Return mission

\section{Introduction}

Earthquake reconnaissance plays an invaluable role in earthquake engineering, as it enables the collection of perishable data on building performance that are otherwise unobtainable. Such data can be used to prepare damage statistics, calibrate and validate engineering models and crucially, to decide what design and/or construction deficiencies lead to inadequate structural performance. In the UK, earthquake field investigations date back to the time of John Milne (1880-1940) (see Musson 2013), and amongst the pioneers of earthquake reconnaissance from an earthquake engineering perspective was Professor Nicholas Ambraseys, to whom this special issue is dedicated. Professor Nicholas Ambraseys, carried out earthquake reconnaissance for dozens of earthquakes between the 1960s and 1980s, many under the auspices of UNESCO (e.g. the Skopje, earthquake of 1963, see Ambraseys 1968). These missions were often very small ad hoc arrangements where researchers made their own way to areas of interest to study the causes and effects of these events.

Today, post-earthquake reconnaissance by highly specialized teams of earthquake engineers is undertaken by several organisations worldwide, e.g. AIJ (Japan), EEFIT (UK), EERI and MCEER (USA), NZSEE (NZ), Geoscience Australia, to name a few. Typically these organisations send a multidisciplinary team comprising seismologists, geologists, engineers, architects and sometimes social scientists, to the field after an earthquake for typically one to two weeks (often longer) to gather information, critically analyse the collected data and produce reports to disseminate their findings. These reports provide valuable information of the earthquake aftermath but do not provide any information on the subsequent earthquake recovery process.

Post-disaster recovery and reconstruction, especially from an engineering perspective, is poorly documented. Apart from the technical challenges, reconstruction planning and the implementation of seismic repair and strengthening solutions are affected by many nonengineering issues, such as workmanship, the availability of skilled labour or appropriate materials, funding, urban development plans, post-disaster migration, local policies and per-

S. Stephens

Atkins, 500 Park Avenue, Almondsbury, Bristol BS32 4RZ, UK

A. Vicini

ImageCat Ltd., Centrepoint House, 2 Denmark Road, Guildford GU1 4DA, UK

W. Shelley

British Geological Survey, Murchison House, West Mains Road,

Edinburgh EH9 3LA, UK

R. Foulser-Piggott

Cambridge Architectural Research Ltd., 25 Gwydir Street \#6,

Cambridge CB1 2LG, UK 
ceptions, amongst others. All these issues vary with location, type and extent of events, and call for engineers to work more closely with architects, planners and disaster managers in order to ensure more resilient cities in the future.

In light of these considerations, in November 2012 EEFIT launched its first ever return mission to an earthquake affected site. A highly multidisciplinary team (see authors) spent 7 days visiting areas affected by the 2009 L'Aquila Earthquake in Italy. The L'Aquila Earthquake, was chosen as being a recent European event of interest to the UK and European earthquake engineering community. EEFIT first visited areas affected by the 6th April 2009 L'Aquila 2009 event in 2009, shortly after the mainshock. Observations from the first mission are presented in Rossetto et al. (2009, 2011), which report the main seismological and geotechnical aspects of the event, the damage observed in buildings and infrastructure and on casualties. To complement this work, the main aims of this return mission were to document repair, strengthening and reconstruction methods, temporary housing, and social recovery post-disasters, and to test field data collection tools.

This paper presents an overview of the post-disaster emergency phase and transition to reconstruction in the Aquila area after the earthquake. It takes an earthquake engineering perspective, highlighting areas mainly of interest to the fields of structural/seismic engineering and reconstruction management. Within the paper, reference is made to published literature, but also to data collected in the field during the return mission that would not otherwise have been available, such as unpublished data, direct field observations made by the EEFIT team and interviews conducted with relevant parties during the return mission. As there is currently significant debate within international earthquake reconnaissance groups (i.e. GEER, EERI and EEFIT) as to whether return missions should be conducted more regularly, the paper ends with some reflections on the value that return missions can provide to the field of earthquake engineering in general, based on the EEFIT L'Aquila experience.

\section{Overview of the 2009 L'Aquila Earthquake}

On 6 April, 2009 (01:32:40 UTC) the M 6.3 L'Aquila earthquake struck the Aterno Valley in the Abruzzo region, central Italy. The focal depth of the main event was about $9 \mathrm{~km}$ along the 15-18 km long NW-SE normal fault with about $45^{\circ}$ dipping SW, matching with the regional fault geometry in the Apennines (Pacor et al. 2011). The 2009 L'Aquila earthquake caused severe damage in 16 municipalities, including L'Aquila, which itself has more than 20 frazioni or separate villages of which one, Paganica, has a population of more than 5,000. Over 60,000 buildings were damaged in the L'Aquila earthquake, the structural damage resulting in 308 deaths, approximately 1,500 injuries and 67,500 people being left homeless (Alexander 2010). The large areal extent of the damage caused by the earthquake, the variety of buildings (i.e. historic, recent residential and industrial) affected and vast number of people left homeless posed severe challenges to the disaster response.

\section{The emergency phase}

The L'Aquila earthquake struck at 03.32 local time on the 6th of April 2009. The early response task force for the emergency was set up and managed by the Civil Protection, with the Executive committee established by 4.15 a.m. The DI.COMA.C. (Direction of Command and Control), the coordinating body set up by the Civil Protection Department, was set up at 9 a.m. in the national training centre of Italy's financial police force (Guardia di Finanze) 
in Coppito, near L'Aquila. The National Fire Brigades took a leading role in the emergency response, contributing to search and rescue, evacuation of the historic centre of L'Aquila and were later involved in safety interventions on damaged residential structures and historic churches. The Civil Protection also assisted the population with shelter, hospitalization and first aid. They also carried out field surveys to assess the damage to buildings, cultural heritage and infrastructure, and gathered information for a detailed macroseismic intensity assessment. The activities carried out by the Civil Protection are reported to have cost around $€ 456$ million (DPC 2010a).

\subsection{Damage assessment}

The Civil Protection emergency team (DI.COMA.C.) coordinated the post-earthquake building damage assessment. Damage assessments were made at a dwelling, rather than building, level. A total of 76,600 inspections on private dwellings and 2,600 on public units were carried out, with peaks of 1,500 dwelling surveys/day (DPC 2010b). This was made possible thanks to volunteers affiliated with universities, local municipalities, industry, the National Research Centre (CNR), and national and local sections of professional institutions (engineers, architects, etc). The first level survey form for post-earthquake damage and usability assessment, AeDES, was adopted to classify each building according to its damage and useability, following the methodology proposed by Baggio et al. (2007). This form is designed for the survey of ordinary buildings used for habitation and/or services. Therefore, the use of this form for the assessment of buildings with particular structural typologies (industrial warehouses, sport structures, theatres, churches, etc.) is excluded. The form allows for a quick survey and a first identification of the building stock, with the collection of metrical and typological data of the buildings.

Tables 1 and 2 summarize the outcome of the usability and damage assessment, at the date of March 2010, when 5,000 engineers and technicians completed the survey on 73,521 dwellings. Although the AeDES forms are not designed for the assessment of cultural heritage buildings, it is observed in Table 1 that they have been used to assess some such structures,

Table 1 Usability assessment of 73,521 damaged dwellings in March 2010 (www.protezionecivile.it)

\begin{tabular}{llll}
\hline & Private buildings & Public buildings & Cultural heritage \\
\hline Usable (A) & $52 \%$ & $53.6 \%$ & $24.1 \%$ \\
Partially usable (B,C) & $15.9 \%$ & $25.2 \%$ & $22.2 \%$ \\
Unusable (E, F) $^{\mathrm{a}}$ & $32.1 \%$ & $21.2 \%$ & $53.7 \%$ \\
Completed assessments & 71,302 & 2,219 & 1,800 \\
\hline
\end{tabular}

a Category D is defined in the AeDES forms as buildings that are temporarily unusable and require further inspection. Buildings in this category were assigned to other usability categories following a second inspection

Table 2 Outcome of the usability and damage assessment in function of the structural type (www.reluis.it)

\begin{tabular}{llllll}
\hline & $\mathrm{A}(\%)$ & $\mathrm{B}(\%)$ & $\mathrm{C}(\%)$ & $\mathrm{E}(\%)$ & $\mathrm{F}(\%)$ \\
\hline Masonry & 48.7 & 10.7 & 2.6 & 31.7 & 6.3 \\
Mixed type & 62.9 & 11.3 & 3.0 & 17.7 & 5.1 \\
Reinforced concrete & 61.6 & 19.4 & 2.3 & 14.6 & 2.1 \\
Total & 52.0 & 12.5 & 2.6 & 27.5 & 5.4 \\
\hline
\end{tabular}


and these are likely to be included within the "masonry" and "mixed type" categories of Table 2.

It is important to note that the AeDES classification of usability was used by the Government to obtain a first evaluation of the earthquake losses and apportion the economic resources for repair and reconstruction. They were also used to guide the amount of resources building owners are entitled to for repair and reconstruction (see Sect. 4).

\subsection{Disposal of rubble}

In the aftermath of the earthquake, the problem of demolition and rubble management arose. Preliminary calculations showed a total rubble volume ranging from 1.5 to 3 million cubic metres were to be dealt with (DPC 2010b). The Italian environmental code (D. Lgs. 152/2006) follows European regulations and is very clear on the fact that soil and demolition material are considered as rubble and should be appropriately disposed of, but it was unclear how the environmental code should be applied in an emergency situation.

Given the amount of material and the substantial difficulty in assessing qualitatively the composition of rubble, the Government promulgated a brand new regulation on the subject (OPCM 3767, OPCM 3771, OPCM 3782, OPCM 3797, OPCM 3813, OPCM 3817), such that during the reconstruction, rubble can be identified and classified as:

1. Rubble of a building damaged or collapsed during the 6th April earthquake, or demolished afterwards for safety reasons.

2. Rubble originating from the retrofit and/or reconstruction of private buildings ("B", "C" or "E" damage category)

3. Rubble originating from small retrofitting works on private buildings ("A" damage class)

To date, 746,418 tons of rubble have been brought to disposal, with more of the $50 \%$ of this during the year 2012 (www.commissarioperlaricostruzione.it). A very efficient and relatively cheap control system was set up to track the rubble chain from site to disposal. Rubble is classified as hazardous or not, based on its nature, identified as suitable for reuse where possible and treated to obtain aggregates for reconstruction or else appropriately disposed of in case of contamination or lack of suitability.

\subsection{Shoring of structures}

Following the earthquake there was an immediate need to ensure the safety of buildings. Hence, an extensive program of shoring works was deployed to stabilize buildings in AeDES classes "B", "C" or "E", while decision on their repair or demolition were taken. This was particularly important in the historic centre of L'Aquila in order to safeguard cultural heritage from further damage caused by aftershocks. These safety interventions were carried out by the Civil Protection with the support of the Ministry of Cultural heritage, Universities and Fire Brigades teams.

Temporary works after an earthquake are mainly an engineering issue, which needs to be solved at two different scales (Grimaz 2011): at an urban level and at the single building level. At urban level, the historic centre is the heart of the community, housing strategic, commercial, governmental and social functions that need to be restored in the least possible time. Route access to and safe use of the buildings that house such functions need to be guaranteed, by clearing debris and by stabilizing adjacent damaged structures. At the single building level delayed collapse of the building through potential mechanisms activated by aftershocks needs to be avoided. 
(a)
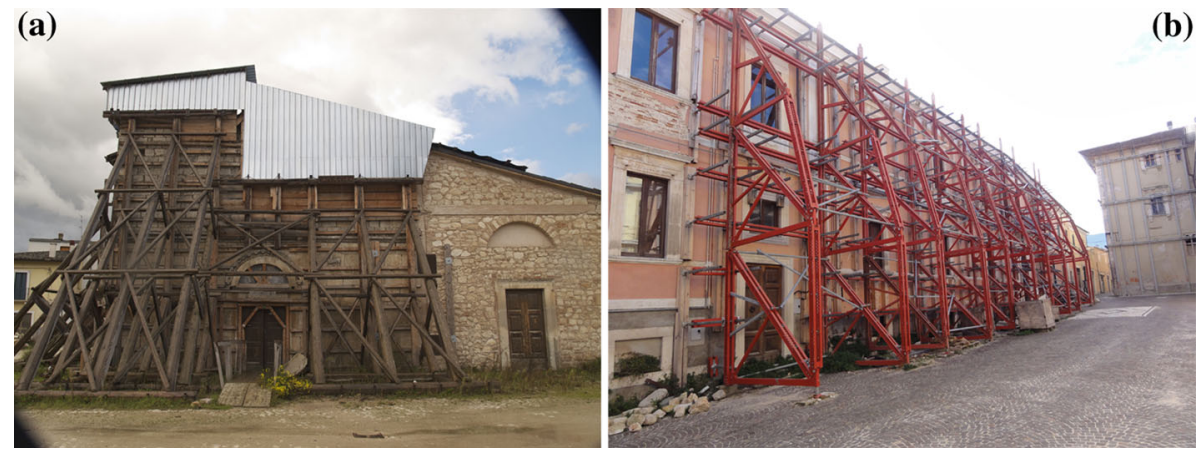

(b)

Fig. 1 Shoring system made of a wooden and $\mathbf{b}$ steel trusses used to prevent out of plane failure of masonry walls/panels
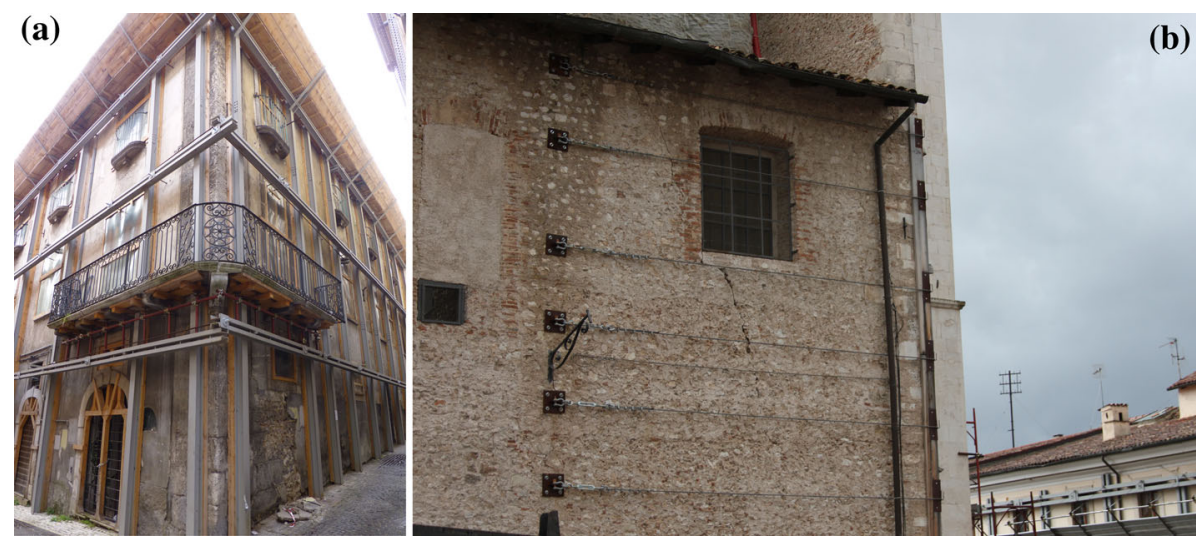

Fig. 2 Shoring system made of a steel frame to prevent combined mechanisms or overturning of the top floor and $\mathbf{b}$ steel cables, to prevent in plane failure and overturning of the corner

The most extensive post-earthquake deployment of temporary works in L'Aquila are shoring structures, since overturning of masonry facades (or parts thereof) is the most commonly observed failure mechanism (Modena et al. 2010). Safety interventions for this failure mode are seen to involve traditional wooden or steel truss systems (Fig. 1). The struts and ties form a buttress that prevents the overturning of the entire façade. The trusses are connected transversally and braced to prevent buckling and create a spatial truss. The possible effect of hammering between the facade and the shoring system, which may be triggered by aftershocks, is prevented by anchoring the top of the propping system to the wall, and the base to the foundation of the wall or to an independent system able of resisting the seismic load. A second system, made of vertical steel posts and horizontal ties is used extensively when floor structures have detached from facades and these show a crack pattern consistent with in-plane failure. Variations on this system comprise horizontally laid wooden planks, polyester straps or steel cables which wrap around the building with the aims of confining the masonry of the façade and of anchoring it to orthogonal walls (Fig. 2). The example in Fig. $2 \mathrm{a}$ is more appropriate when the connection between adjacent facades needs securing or when a combined mechanism causing out-of-plane failure of the façade and in-plane failure of its orthogonal walls is present. The steel cable system shown in Fig. $2 b$ is suitable for 


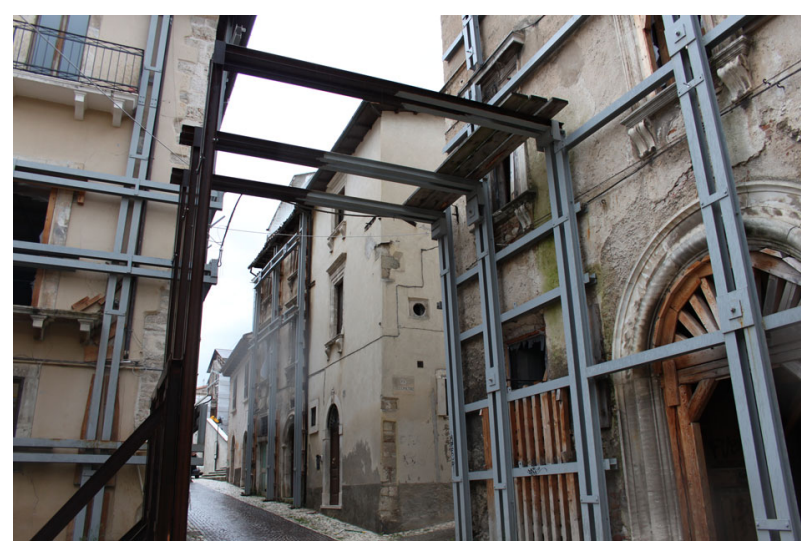

Fig. 3 Shoring system applied to buildings facing onto a narrow street

restoring the box behaviour of buildings with corner failures. In cases where the causes of failure are likely to comprise both in-plane and out-of-plane failures, a combination of the two shoring systems is required (Modena et al. 2010).

The types of system used for shoring depend not only on the type of the developed/potential mechanism, but also on the location of the building, its connection to adjacent buildings and their state of damage, the outer space available and the ease of access. An alternative shoring system to the traditional one, shown in Fig. 3, was observed for buildings belonging to building aggregates, which exhibited out-of-plane failure of a façade facing onto a narrow street. This system comprises a series of vertical composite posts connected transversally at every metre or so depending on the geometry of the façade, and is contrasted to a paired system on the other side of the street. Both are independently anchored to the ground. This intervention also prevents overturning of opposite façades facing onto the same street and guarantees access by creating a safe passageway. Finally, propping systems made of wooden struts are often applied to openings and support horizontal structures in order to make them reasonably safe for recovery interventions.

Many of these shoring systems, implemented in 2010, are still in place at the time of writing, as relatively few interventions of repair and restoration have taken place in the historic centre of L'Aquila, although activity was re-started at the end of 2012. Indeed in the document "Raccomandazioni per la realizzazione delle opere provvisionali", annex B to the DI.CO.MAC prot no 8033 of 05/05/2009 (www.protezionecivile.it), it is explicitly stated that, based on previous reconstruction experiences in Italy, the shoring should be implemented with materials that are not greatly affected by weathering. It proceeds to recommend that steel components be used. One of the issues that remain open in any of the provisions inspected, especially the ones with post-tensioned elements, either plastic or steel, is how effective they currently are after having been in place four years. It was not possible to assess this in the short timeframe of the EEFIT mission, however, it is expected that the effectiveness of these interventions will degrade if they are not regularly inspected and maintained, and eventually re-tensioned.

Shoring of existing structures was almost exclusively used for masonry structures, with very few observations of reinforced concrete buildings. It is considered that the primary reason for this relates to the number, vulnerability and historical significance of the masonry structures viewed. However, a secondary explanation relates to the inherent residual strength 

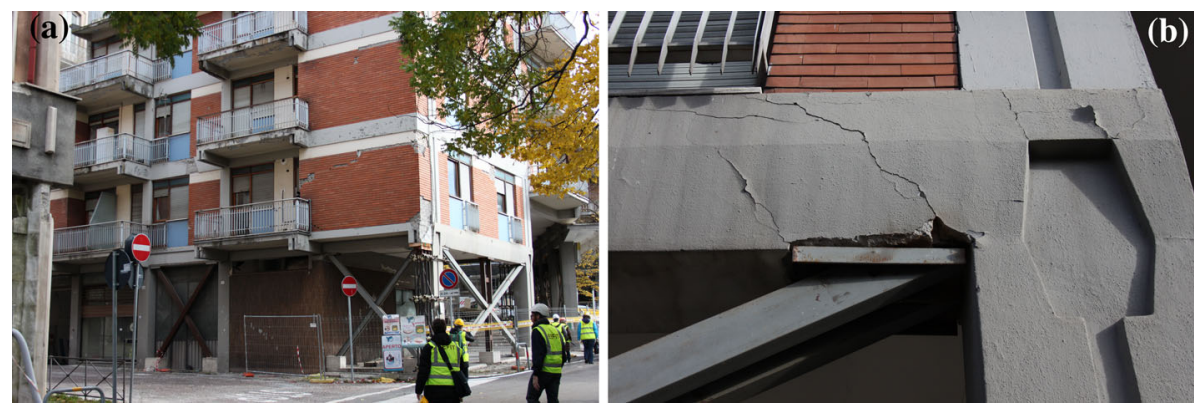

Fig. 4 Shoring of a Reinforced Concrete structure to prevent soft storey collapse. a Building elevation b shoring bearing against existing structure

of reinforced concrete structures that are stable in the temporary condition but require retrofit to return them to full service. It should also be noted that severely damaged reinforced concrete structures had either collapsed or been demolished at the time of the EEFIT return mission.

An example of where a reinforced concrete structure had been temporarily shored, is shown in Fig. 4, where ground floor bays of the structure were propped with back-to-back steel channel cross bracing. In this instance the building has susceptibility to a 'soft storey' collapse that is mitigated by the shoring system selected.

\subsection{Microzonation studies}

The variability of the damage distribution in the Aterno valley has been widely associated with site effects (both soil and topographic amplification) highlighting the need for a rigorous microzonation study. Microzonation studies are essential to first flag areas vulnerable to site effects and then to quantify potential amplification of the ground motion (ideally for various hazard levels), which in turn is important for urban planning, post-earthquake reconstruction and rigorous structural design.

An extensive geotechnical investigation was conducted after the earthquake at sites in the historic city centre and suburban area of L'Aquila in order to obtain input data for site seismic response analyses to support the design of repair and strengthening measures for important public buildings. In particular, Amoroso et al. (2011) present a review of results obtained by seismic dilatometer tests (SDTM) executed in the area of L'Aquila between 2009 and 2011. Some of these tests were carried out in the first months following the earthquake, as part of investigations planned for the geotechnical characterization of sites selected for the construction of new temporary houses (C.A.S.E. Project, see Sect. 5.1). SDMT results have also been used, together with down-hole, surface wave (MASW) and refraction microtremor (ReMi) tests, in the seismic microzonation project of the area of L'Aquila promoted by the Italian Department of Civil Protection (MS-AQ Working Group 2010). In addition, four deep boreholes (from 100 to $300 \mathrm{~m}$ below ground surface) have been performed in the historic centre of L'Aquila during the period between June and August 2010 to detail the geological setting of the city subsoil and give specific indications regarding the depth of the bedrock (Amoroso et al. 2010).

The SDMT test procedure consists of the combination of the mechanical flat dilatometer (DMT) with an add-on seismic module for measuring the shear wave velocity $\mathrm{V}_{\mathrm{S}}$ of soil deposits. It was observed to be an effective, quick and cost-saving alternative to conventional 
Down-Hole tests in soft to firm soils (e.g. Mayne and Schneider 1999). A disadvantage of the SDMT is the impossibility of penetrating very hard soils. However, a new procedure for obtaining SDMT $\mathrm{V}_{\mathrm{S}}$ profiles in non-penetrable soils (e.g. in gravel or even in rock) was developed by Totani et al. (2009) using boreholes backfilled with sand. This new technique has been extensively used at several sites in the historic centre of L'Aquila (i.e. Piazza del Teatro, Palazzo Camponeschi, Palazzo Carli, Fontana 99 Cannelle) and in the suburban areas (i.e. Cese di Preturo, Pianola, Roio Piano, Santa Rufina, Ponte Rasarolo on the Aterno River), characterized by the presence of mostly coarse-grained non-penetrable soils. In most of the above sites the maximum test depth has been 16-23 m, while in some cases the backfilling procedure permitted $\mathrm{V}_{\mathrm{S}}$ measurements to be obtained by SDMT down to very large depths (i.e. Palazzo Camponeschi and Fontana 99 Cannelle).

The site investigations results indicate that the upper portion of the subsoil in the city centre generally consists of up to $100 \mathrm{~m}$ of "Megabreccia" formations (composed by fine to coarse calcareous fragments embedded in sandy-silty matrix with highly variable degree of cementation), overlying fine to medium grained lacustrine deposits of more than $200 \mathrm{~m}$ depth placed on the calcareous bedrock. The shear wave velocity in the "Megabreccias" generally increases with depth from about 400 to $1,200 \mathrm{~m} / \mathrm{s}$, with some dispersion essentially due to the variability in the silty-sandy matrix and its cementation. In the underlying lacustrine silt, investigated by SDMT up to a depth of $133 \mathrm{~m}$ at the site of Fontana 99 Cannelle, the measured $\mathrm{V}_{\mathrm{S}}$ values range between 400 and $600-700 \mathrm{~m} / \mathrm{s}$. These results highlight the presence of an inversion of the shear wave velocity with depth in the subsoil of the historic centre of L'Aquila.

SDMT tests have also been performed in backfilled boreholes at various sites located in the western outskirts of the town, in the densely populated districts of Coppito (including the sites of San Salvatore Hospital and the strong motion station AQA-Aterno River, part of the Italian Strong Motion Accelerometric Network RAN), Pile and Pettino. The $\mathrm{V}_{\mathrm{S}}$ measured at the above sites, mostly in gravel or calcareous breccia, results generally higher than $400 \mathrm{~m} / \mathrm{s}$ and increases with depth, reaching values of the order of $1,000 \mathrm{~m} / \mathrm{s}$ at $15 \mathrm{~m}$ below ground surface.

The accurate definition of the shear wave velocity profiles described above, in conjunction with advanced laboratory investigations of the soil shear stiffness degradation with cyclic strain and related hysteretic dissipation (through resonant column, torsional shear and cyclic simple shear tests), has allowed a detailed seismic microzonation study of L'Aquila city centre and its suburban area (MS-AQ Working Group 2010). Site specific response spectra have been generated for twelve different macroareas using one- and two-dimensional numerical approaches. The rock input motions for the numerical simulations have been obtained through the definition of uniform hazard spectra derived from a probabilistic evaluation of timedependent seismic hazard and from the evaluation of the seismogenetic potential of the faults in the area. It should be noted that the uniform hazard spectrum has been shown to be conservative for long return period earthquake shaking and the conditional mean spectrum has been recently proposed as a more appropriate target for ground motion selection (e.g. Baker and Cornell 2006; Cimellaro 2013).

The results of the microzonation study have highlighted a consistent under-prediction of the spectral accelerations at short periods using the response spectra proposed by the Italian seismic regulation (NTC 2008), especially for areas where the inversion of the shear wave velocity with depth was observed in-situ.

\section{Transition to reconstruction}

A post-emergency phase began in February 2010, 9 months after the mainshock (Chiodi 2012) and signaled the start of reconstruction. 
One important engineering aspect of this plan and of the transition period was the clear definition of a normative framework for building repair, strengthening and reconstruction. The Government appointed the President of the Abruzzo Region as Commissioner of Reconstruction, (OPCM n. 3833/ 22 December 2009 and DL 195/2009), who was responsible for the coordination and end of damage assessment activity on the buildings, the definition of a regulatory body and an approval process for reconstruction, for setting up a checking and approval structure for the technical and economic management of submitted building designs and applications for funding. During both the emergency and the transition phase, the Commissioner for Reconstruction was given the authority to take action without having to adhere to the current Italian regulations for contracts and execution of public works. Several new regulations were proposed to the Government and promulgated as Ordinances of the Prime Minister (OPCM), or as Decrees of the Commissioner for Reconstruction (DCD). Between February and August 2012 these counted approximately 36 and 130, respectively (Chiodi 2012). The role of the Commissioner for Reconstruction came to an end in 2012, with the state of emergency declared as being over (31st of August 2012, after L134/2012). The reconstruction process is now ongoing, with each procedure following the normal system and observing the current Italian regulations on Contract and execution of public works. The two different strategies adopted in the approval for strengthening and rebuilding works in the historical centre of L'Aquila and its surrounding suburbs is described in more detail here.

\subsection{The "Filiera" and the approval process for strengthening and rebuilding the suburbs of} L'Aquila

In order to deal with the numerous applications for repair, retrofitting and reconstruction of the earthquake affected buildings, the Commissioner for the Reconstruction, as ratified by the decree-law 39/2009 (subsequently substituted by the law 77/2009), created a procedural body, the "Filiera" to process all building applications. This body is composed by one share company, FINTECNA SPA, and two consortia, ReLUIS and CINEAS. It is referred to as "Filiera", the Italian word for 'supply chain', because of its approval system, which is characterized by a chain sequence. The Filiera's duties in L'Aquila are to review all the project applications for private building reconstructions that are eligible for a state contribution, and to allocate grants.

ReLUIS is the Consortium of the Italian Seismic Engineering Laboratories Network (Rete dei Laboratori Iniversitari di Ingegneria Sismica), instituted as a non-profit organisation with the purpose of coordinating activities of member University Laboratories in seismic engineering (www.reluis.it). In L'Aquila, ReLUIS acted as technical consultant for all the municipalities of the L'Aquila province, auditing and approving engineering interventions on private residential and industrial buildings. It is noted that the historical centre of L'Aquila falls outside their remit. To ensure a rapid and successful collaboration, ReLUIS engineers liaised directly with the engineers that submitted designs for approval. Designs have to be submitted for each dwelling in the damaged property as well as for the communal areas in the building. Buildings were re-modelled, assessed and discussed personally with the designer. Frequently the application process needed multiple iterations before achieving the approval status (personal communication, Engineer of ReLUIS).

It should be also noted that in January 2008 the Italian Government published a new release of the Italian Building Code, entirely based on the Eurocodes. The transition from the previous code to the new one was planned to last until June 2010, however, after the $6^{\text {th }}$ April 2009 earthquake, the new Italian Building Code became immediately compulsory for 
new constructions specifically to promote the seismic resistant design of new buildings and strengthening works.

In L'Aquila the ReLUIS outfit comprises about 30 individuals, all based in the training centre of the financial police in Coppito. Weekly lectures were organized with third parties to disseminate technical requirements and several guidelines were written and published by ReLUIS to aid practitioners to achieve designs that would gain technical approval (www. reluis.it). The following key points were highlighted as resulting in a successful technical check (personal communication, Engineer of ReLUIS):

1. Consistency between the proposed works and the reported damage.

2. Consistency between the proposed strengthening works and the seismic appraisal of the structure, as regulated by the Italian Building Code.

3. Consistency between local strengthening works, seismic appraisal of the structure and the design guidelines published by the Civil Protection.

A deadline of the 31st August 2011 was imposed on building owners for submitting applications for reconstruction (the initial deadline imposed by OPCM 3790/2009 was postponed several times by other five different OPCMs, the last of which was OPCM 3950/2011). In total, 7447 designs (Chiodi 2012) were submitted by this deadline. The aim of imposing a strict deadline for design submission was to promote a rapid reconstruction. However, it instead resulted in poor quality designs being submitted, which often required multiple design iterations. ReLUIS are required to assess any application received within 60 days of its submission. If not approved, a designer has 30 days to improve/change the design and resubmit. ReLUIS then have another 30 days to recheck and approve/reject the design. Up to three iterations were possible in the last two steps (personal communication, Engineer of ReLUIS). This led to delays in the technical approval of the design packages, highly criticized by the media and the public. Furthermore, as no limit was set as to the maximum number of building designs that could be taken on by any one engineering firm, many local firms were dealing with more jobs than they had a capacity for, thus delaying further the time for completing a design iteration (personal communication, Engineer of ReLUIS).

CINEAS is the Italian Insurance Engineering University Consortium (Consorzio Universitario per l'Ingegneria nelle Assicurazioni), which is responsible for assessing the adequacy of grant applications submitted for repair/reconstruction. Based on the class of damage, the grant is assured on a fixed price per square meter. When the technical review is completed, CINEAS must verify that the request for refunds is compliant, and if it is compliant, recommend that FINTECNA proceed to make the payment; FINTECNA SPA. being the third member of the "Filiera" procedural body referred to earlier.

FINTECNA SPA. is $70 \%$ owned by the Cassa Depositi e Prestiti (CDP_Deposits and Loans Fund) of the Ministry of Economy and Finance and $30 \%$ by a group of bank charities. Its mission is to support national economic growth by funding public administration, finding capital for infrastructure development and supporting national business investments. The law 77/2009 ratifies the intervention of FINTECNA in supporting the reconstruction of L'Aquila Province as an administrative body, which directly (or through the intermediary FINTECNA Immobiliare, one of its subsidiaries) allocates funding to individual beneficiaries for the reconstructions or retrofit of private buildings. FINTECNA also operates as guarantor of the administrative procedure that involves the two consortia, CINEAS and ReLUIS, and as such, it supervises the whole procedure, from the application submission to the allocation of money. FINTECNA furthermore set up and control the Database of Emergency (BDE). This database is a platform for collecting information on people, buildings and plans. The database shares the data amongst the operators of the Filiera and the public authorities. 


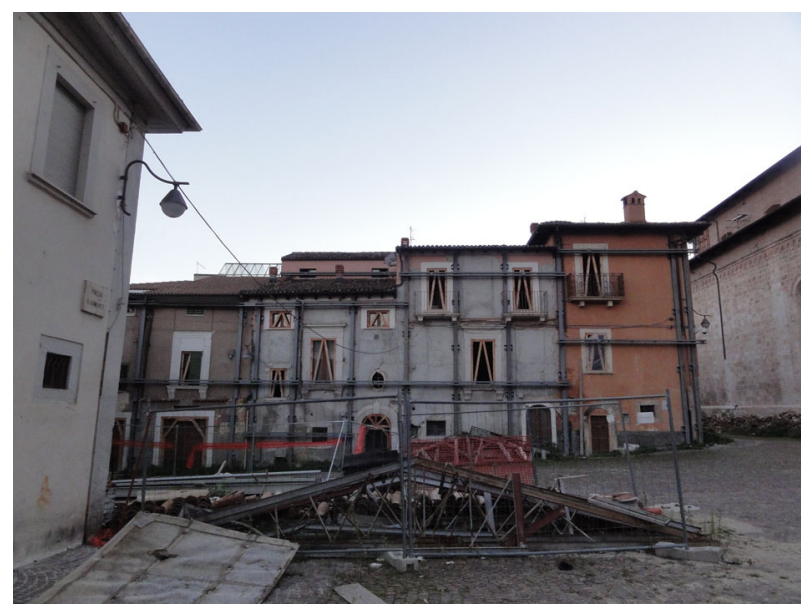

Fig. 5 Example of an aggregate: four distinct building units sharing party walls

The Filiera's mandate ended at the end of 2012. To achieve a smooth handover of the building approval process to the Municipalities, at the end of the Filiera's support period the ordinance 3803/2009 of the Prime Minister established that CINEAS and RELUIS must provide training sessions to municipal employees.

\subsection{Strengthening and rebuilding L'Aquila historic centre}

The reconstruction of the historic city centre of L'Aquila has followed a different procedure than the city suburbs, dictated by the higher density of the urban fabric, the higher incidence of heritage buildings and the higher mean level of damage (approximately $70 \%$ of the historic palaces of L'Aquila have been classified as damage level B or higher). In the strategy for reconstruction, building units in the historic centre are grouped into aggregates, i.e arrays of construction units forming a single urban block and sharing loadbearing walls and other structures (e.g. Fig. 5). As units were registered in the cadastral maps as independent, the first legislative step in the reconstruction was to devise a legal procedure to identify such aggregates.

A deadline of 30th September 2010 was set by OPCM 3820, OPCM 3832 and OPCM 3870 , for all councils within the L'Aquila area to identify which buildings form aggregates, and for the owners/occupiers of the aggregate to constitute legal consortia, which would constitute a single legal entity for the disbursement of the reconstruction funds. Such a consortium is only valid if $51 \%$ of the plan area of the aggregate is represented by the owners subscribing to it. The consortia need to appoint a technical team that will deal with the repair/reconstruction of each single unit, and a team coordinator who will ensure the compatibility of approaches to restoration across the aggregate. Although the aim is to have a unified approach to restoration, to speed up the works, it was allowed for single units to present individual projects as long as compliance with the overall restoration strategy could be proved. Differently from what is seen for buildings outside the historic centre, this approach for aggregates means that buildings classified in classes $\mathrm{B}$ and $\mathrm{C}$ can receive an increment up to $30 \%$ of the funds initially deemed necessary, if they are in an aggregate with at least one building classified as damage class E. This is because the ultimate aim is an 


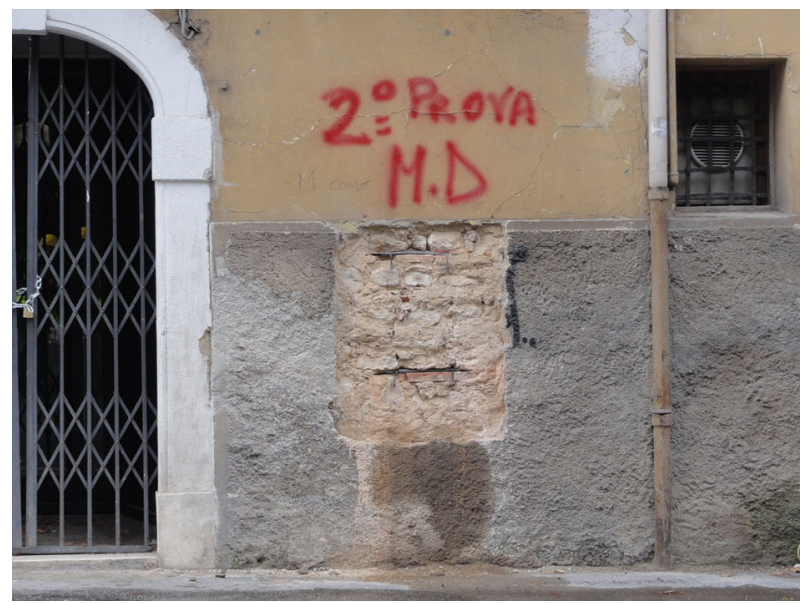

Fig. 6 Photo of typical double flat-jack test to determine compressive strength and mechanical characteristic of masonry

upgrade or improvement of the seismic behaviour at the global level of the aggregate, and less damaged buildings might need substantial intervention to reach homogeneity of behaviour with buildings that are more severely damaged and more heavily retrofitted (Commissario per la Ricostruzione 2011).

Two classes of intervention were considered: local strengthening or overall seismic improvement. Whether an aggregate should undergo either of the two strengthening strategies is dependent on the worst outcome of any unit within it.

The guidelines issued by the Ministry of Cultural Assets and Activities of "Linee Guida" (Circolare n. 26, 2010) identify three phases for repair and restoration projects. As part of the initial technical documentation it is required that for each building a set of in situ semi destructive tests, including plaster removal, masonry fabric classification, coring, single and double flat jacks test (see Fig. 6), are performed to determine the mechanical characteristics of the masonry. The decision on the number and distribution of such tests is left to the engineer.

\subsection{The cost of reconstruction}

$€ 2,861$ Million were spent by the Italian Government for the emergency phase of the earthquake. A further $€ 3,207$ million (out of $€ 10,491$ million made available by the Italian Government) has been spent so far for the reconstruction, (Chiodi 2012).

As of the latter part of 2012 (time of the EEFIT Mission), the "Filiera" (see Sect. 4.1) had approved most of the 27,000 repair projects that had been received with requests for around $€ 4$ billion and payments made of $€ 2$ billion (L'Aquila municipality data service 2012). This did not include the historic centre of L'Aquila which is outside their remit. Hence, these repairs mainly involve reinforced concrete structures. As can be seen in Fig. 7, over $90 \%$ of the about 20,000 repair or replacement projects authorized were in the higher damage categories "B", "C" and "E" categories. It should be noted that the 20,000 projects correspond to approximately 5,000 buildings since individual submissions are required for each dwelling and for communal areas within apartment blocks. 
Fig. 7 Mean repair and reconstruction payments requested/made as of November 2012. Data source: (L'Aquila municipality data service 2012)

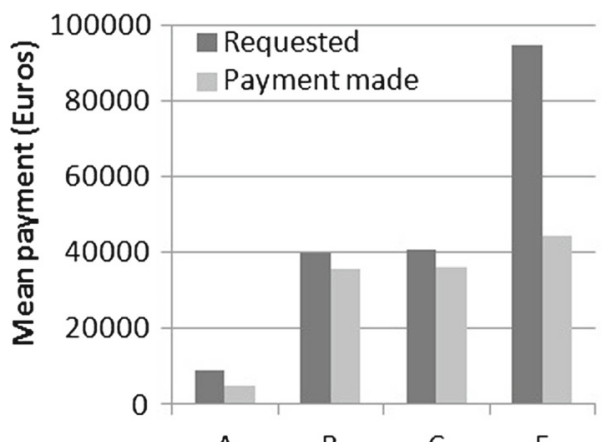

A $\quad$ B $\quad$ C $\quad$ E

Damage/usage category

Table 3 Summary of repair cost guidelines (OPCM3790)

\begin{tabular}{|c|c|}
\hline Damage category & Repair cost guidance \\
\hline Usable (A) & $\begin{array}{l}\text { Repair with a maximum reimbursement of } € 10,000 \\
\quad+€ 2,500 \text { per apartment }\end{array}$ \\
\hline $\begin{array}{l}\text { Partially usable (B,C and E with light or no } \\
\text { structural damage) }\end{array}$ & $\begin{array}{l}\text { Full refund of repairs of the structural and } \\
\text { non-structural parts, with } 150-250 € / \mathrm{m}^{2} \text {. No } \\
\text { funding for additional earthquake strengthening }\end{array}$ \\
\hline Unusable (E) & $\begin{array}{l}\text { Full refund of repairs and seismic strengthening } \\
\text { works to up to } 80 \% \text { of current hazard level and } \\
€ 80,000 \text {, with } 400-600 € / \mathrm{m}^{2} \text {. If the cost of works } \\
\text { exceeds } 1,200^{\mathrm{a}} € / \mathrm{m}^{2} \text { (limit of economic } \\
\text { convenience), then the building should be knocked } \\
\text { down and rebuilt }\end{array}$ \\
\hline Collapsed buildings & $\begin{array}{l}\text { Reconstruction or replacement for collapsed } \\
\text { buildings }\end{array}$ \\
\hline
\end{tabular}

a $2,200 € / \mathrm{m}^{2}$ in case of listed buildings

Of the total number of projects received about 15,000 were for primary residences (dwelling units or houses). In terms of the mean paid out for primary residences, dwelling units sustaining damage level " $A$ " typically receive less than $€ 10,000$, damage level " $B$ ", "C", and "E" receive about $€ 40,000$ but in the case of dwellings in damage level "E" the requested funds are nearer $€ 100,000$. These values may change after all payments are made but indicate a trend which is consistent with guidelines on payments, shown in Table 3. For example, a typical $4 / 5$ storey reinforced concrete apartment block subject to the $400 € / \mathrm{m}^{2}$ criterion for category " $E$ " could result in a repair cost of the order of $€ 1$ million, which is in line with EFFIT observations of construction sites in the field.

It is important to note that seismic strengthening is only financed for buildings that sustained damage level "E". In these cases, funds can cover the costs of strengthening the structure to $80 \%$ of the current seismic code force requirements. If $100 \%$ compliance with the current seismic code is desired then the owners must pay the additional strengthening costs themselves. Hence, in the case of base isolation, where $100 \%$ can be achieved, OPCM3790 states that the cost to the owner is the cost required to go from an isolator that provides $80 \%$ compliance to one that provides $100 \%$ compliance.

An important consequence of this financial policy is that only those buildings that were severely damaged will likely be strengthened. Hence, those lightly damaged or undamaged 
by the L'Aquila earthquake (e.g. because of distance from this particular fault) will remain vulnerable to the next earthquake event.

\section{Observations on Temporary Housing}

The 2009 L'Aquila earthquake left approximately 67,000 people homeless (Alexander 2010). Those left homeless were roughly equally divided between those who (willingly or through necessity) found their own accommodation, those who were accommodated in the tent camps and those who were sent to hotels.

The provincial structure, divided in several frazioni, as well as the high level of destruction in the city centre, (the most populated part of L'Aquila), were among the reasons why several peri-urban vacant or agricultural lands were selected to settle new transitional constructions. Unlike previous Italian disasters, in L'Aquila the typical framework of providing emergency shelter, quickly followed by temporary accommodation and finally permanent reconstruction, was not adopted. Instead, the precarious phase of emergency shelter was purposely lengthened by several months to permit the construction of transitional houses of high standards, destined to last for several years (Calvi and Spaziante 2009). Seventeen days after the earthquake, the Italian Government took the decision to proceed with two different solutions: the C.A.S.E. project, Complessi Antisismici Sostenibili e Ecocompattibili (Antiseismic, Sustainable and Ecologically Compatible Housing Complexes), and the M.A.P. solution, Moduli Abitativi Provvisori (Temporary Inhabitable Modules). The C.A.S.E. buildings aimed to house people who used to live in the city of L'Aquila, whilst the M.A.P. aimed to house people from the frazioni and tended to be located closer to the towns of the inhabitants. On 22 May 2009 tenders were issued to design and construction companies and on the 8 June, (remarkably soon afterward), construction of the first units began. The aim was to have them built and occupied before the winter, so that people could be moved out of tents before cold weather made them uninhabitable.

\subsection{The C.A.S.E project}

The last building of the C.A.S.E. project was completed on 19 February 2010, although many of the apartments had been occupied by the previous October and November (DPC 2010c). At the end of February 2010, 13,408 people had been accommodated in the C.A.S.E. units, which had a projected maximum capacity of about 17,000 inhabitants (DPC 2010d). The 19 sites of the C.A.S.E. project comprised 185 buildings and 4,450 apartments, mostly of $40 \mathrm{~m}^{2}$. Each C.A.S.E. buildings consist of a 3-4 storey apartment block of typically wood frame or steel construction that sits on a large $500 \mathrm{~mm}$ thick reinforced concrete plate supported on base isolators mounted on reinforced concrete columns (see Fig. 8a). In many cases a substantial amount of costly ground works have been carried out to site the buildings at the foot of hills. The total cost of building averaged $€ 280607$ per apartment (Calvi and Spaziante 2009), of which about one third was attributable to the structure and two-thirds to the landscaping and urbanization works (e.g. paving roads, planting trees. site technological infrastructure). This is a very high price if compared to the cost of the MAP (see Sect. 5.2) and of the average repair and strengthening cost of dwellings stated in Sect. 4.3.

On 31 March 2010 the Italian Department of Civil Protection ceded the responsibility for the C.A.S.E. buildings to the Municipality of L'Aquila. Maintenance was outsourced to a private cooperative, Manutencoop. In 2011 the L'Aquila Municipality published the Reconstruction Plan, a revised edition of the Strategic Plan for the future of L'Aquila, which 

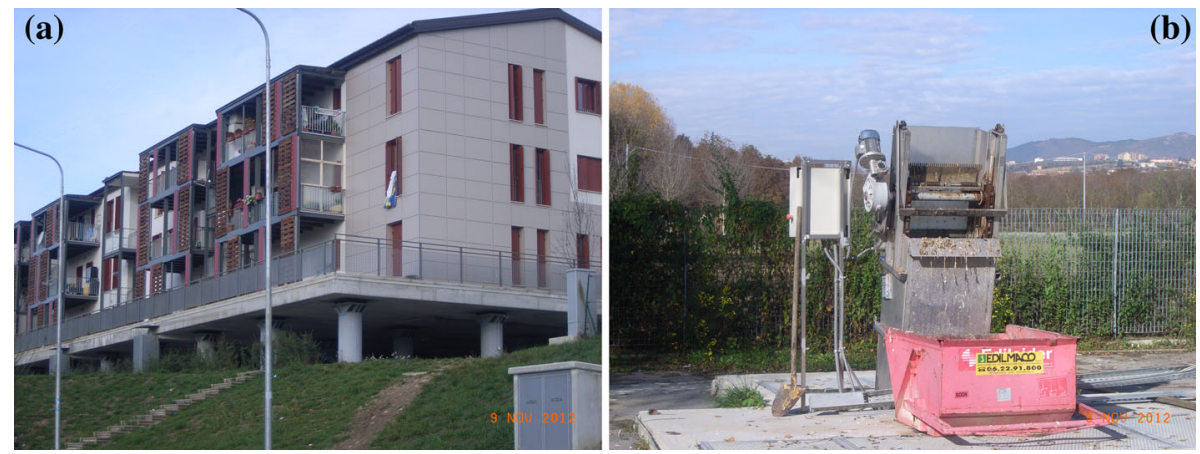

Fig. 8 Photograph of a C.A.S.E. building in the Bazzano site (a), and the inadequate sewage filtering site alongside the Aterno river (b)

was published just before the earthquake. One of the main issues discussed in the plan is the legacy of the C.A.S.E. settlements (locally termed "New Towns") in a perspective of reshaping the suburban configuration. The Plan envisages the necessity to change from a single-centred city model to a multi-centred model; it sees the frazioni as adding new value to the city (Comune di L'Aquila 2011, p. 42). It promotes a change from the C.A.S.E. sites providing only a residential function to a multifunctional offer of spaces and services. The latter was strongly requested by the municipality in the planning phase of the C.A.S.E. sites, in fact, $30 \%$ of the 19 New Towns' gross surface (percentage defined by the General Regulatory PlanComune di L'Aquila 2011) is reserved for public facilities with social provisions (schools, health centres and parks) and facilities for locally based commercial activities (food shops, laundry services, tobacco stores, stationaries, bars, professional studies and bank offices). A fundamental aspect of the plan is to balance the depopulation of the C.A.S.E. siteswhich will characterize the settlements while people will progressively return to their rebuilt or repaired houses - through the "inclusion of new social groups: young couples, students, teaching staff, researchers, artists, touristic receptivity, etc.", supported by a more efficient delocalised network of social services (Comune di L'Aquila 2011, p. 43).

The C.A.S.E. project has often been held up as an example of rapid, effective response to the need for safe mass housing after an earthquake (Calvi 2010; Consenza and Manfredi 2010). However, in many cases, the vision has not become reality. In synthesis, it has a number of pros and cons, as described in Table 4. In particular the name "Antiseismic, Sustainable and Ecologically Compatible Housing Complexes" is questionable given the lack of appropriate waste water purification (see Fig. 8b) resulting in effluent being only filtered (and possibly treated with few chemicals) before being released into the Aterno river.

Comprehensive surveys of the 19 C.A.S.E. sites were conducted over the period March 2010-January 2011 under the aegis of the MICRODIS FP6 European-funded project (see http://www.microdis-eu.be). The surveys were designed to measure the provision of services at the various sites and the level of social dystopia present among their inhabitants. At the time of the MICRODIS survey the C.A.S.E. settlements had been established but had not matured. One of the tasks of the EEFIT return mission was to ascertain whether the situation had changed. In substance some improvements had been made, but significant changes were observed only at a few sites. Many of the sites had gained public transport provided using small buses that are able to negotiate the corners and turns in the sites, which by and large were not designed to accommodate larger buses. In two complexes, Coppito 3 and Cese, new buildings were constructed in late 2012 that were apparently destined to be used as 
Table 4 Summary of positives and negatives of the C.A.S.E. project

\begin{tabular}{|c|c|}
\hline Positives & Negatives \\
\hline $\begin{array}{l}\text { Widespread use of solar and photovoltaic panels } \\
\text { to reduce carbon emissions }\end{array}$ & $\begin{array}{l}\text { Unregulated consumption of prime farmland and } \\
\text { conservation land by compulsory purchase } \\
\text { without public discussion }\end{array}$ \\
\hline $\begin{array}{l}\text { Careful use of insulation; other energy } \\
\text { conservation measures }\end{array}$ & $\begin{array}{l}\text { Unsystematic siting with respect to people's } \\
\text { travel needs (work, school, shopping, etc.) }\end{array}$ \\
\hline $\begin{array}{l}\text { Landscaping and external appearance designed } \\
\text { to create harmony with the surrounding } \\
\text { environment }\end{array}$ & Lack of waste water purification facilities \\
\hline Economical use of materials & Lack of basic services \\
\hline $\begin{array}{l}\text { Protection against earthquakes by the use of base } \\
\text { isolators }\end{array}$ & $\begin{array}{l}\text { Social fragmentation and social pathologies } \\
\text { (depression, post-traumatic stress disorder, } \\
\text { xenophobia, domestic violence, substance } \\
\text { abuse) }\end{array}$ \\
\hline $\begin{array}{l}\text { Parking under the base isolated foundations of } \\
\text { the buildings in a protected but not prominent } \\
\text { location }\end{array}$ & $\begin{array}{l}\text { Questionable quality of maintenance of the } \\
\text { buildings and their surrounding environment }\end{array}$ \\
\hline $\begin{array}{l}\text { Lifts and ramps to ensure the accessibility of } \\
\text { apartments. }\end{array}$ & Elevated costs of construction \\
\hline
\end{tabular}

social centres for these complexes. Bazzano, one of the largest C.A.S.E. sites, has acquired a complex of prefabricated buildings which is used as a nursery school and which was donated by FIAT SpA. Sant'Elia 2 has a small parade of basic shops situated in a nearby row of buildings that have recently been adapted for retail use. Other complexes, including some of the largest, still have no facilities other than housing, children's playgrounds and parking spaces.

The state of maintenance of the C.A.S.E. buildings remains adequate, but it is not clear how long this situation will prevail. Coppito 3 has landscaping problems, in that the state of maintenance of the public open space is very poor. When they were interviewed, residents complained about difficulties and delays in getting repairs done.

\subsection{M.A.P.}

By 28 February 2010 1,710 people had been accommodated in MAP units in the municipality of L'Aquila and 2,585 in the MAP complexes of other towns (DPC 2010d). Overall, the MAP project cost the Italian government €236 million and involved the deployment of 2,262 units (DPC 2010e). A total of 1,273 MAP units were built at L'Aquila, of which $88.5 \%$ were funded by the national Department of Civil Protection. Outside the municipality of L'Aquila, 1,909 MAP units were installed at 113 locations in 50 municipalities. The largest sites were at Barischiano (106 units) and Fossa (86 units).

The moduli abitativi provvisori (MAP) are a development of the standard light-walled prefabricated dwellings that have been used in Italy after earthquakes for many decades. The present versions consist of square or oblong units of 40,50 or $70 \mathrm{~m}^{2}$ floor space constructed with a wood frame and fiberglass-insulated wood paneling infill (e.g. Fig. 9). The unit is anchored to a concrete base plate, and the roof may be built of corrugated steel or terracotta pantiles. In the latest version, variants have been designed and constructed, for example, San Gregorio, the units have two storeys. During the EEFIT mission it was noted that the quality of construction of the MAP varies significantly between different sites, with, for example, 


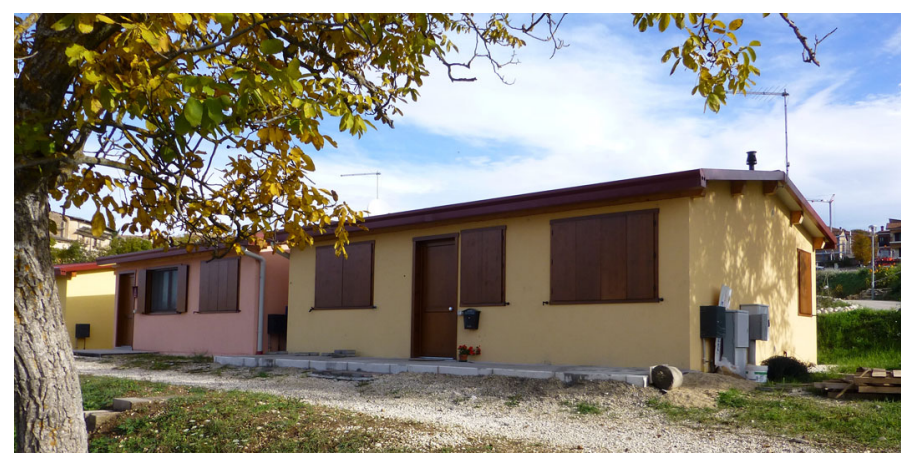

Fig. 9 Example of a MAP house in Fossa

maintenance problems (e.g. water infiltration) being observed at San Gregorio, where the quality of construction appears significantly worse than in Onna.

When they were first inaugurated, most of the MAP sites were as deprived of services as were the C.A.S.E. sites. This situation has changed, in some cases, faster and more substantially than that of the C.A.S.E.

At Onna, 47 duplex MAP units were constructed under the auspices of the autonomous province of Trento, giving a total of 94 apartments; with floor spaces variously of 45, 52 and $74 \mathrm{~m}^{2}$ (DPC, 2009). These were built of high quality timber originating from Trento, and financed entirely by the Red Cross for a total cost $€ 5.2$ million (Calabrese 2010). This translates to an average cost per apartment (not accounting for differences in floor plan) of $€ 55,319$, one fifth of the cost of an apartment in the C.A.S.E. project. Onna subsequently acquired an elementary school, an indoor recreational facility, a community centre and a church. The MAP site at Fossa presents another example of progress. Here, 86 single-storey MAP units were constructed under the auspices of the autonomous region of Friuli VeneziaGiulia. Fossa soon acquired a substantial church, built with a laminated wooden frame and a wooden campanile. By late 2012 a pharmacy, a bar and a small supermarket had been added, and a community meeting hall was ready for occupation. A town hall and a post office will also be built soon.

The situation at Fossa, however, illustrates one of the main problems of post-disaster transitional housing: it is intended to be temporary but rapidly acquires the trappings of permanence. Over the years, in Italy, prefabs have become progressively more expensive as they have become more sophisticated (though they are still significantly less costly than the C.A.S.E. project). The settlements in which they are installed have begun to gain urban functions. These confer yet more of a sense of permanence on the settlements, yet they are surrounded by prefabricated dwellings that are not appropriate for long-term inhabitancy.

\section{Repair and strengthening of buildings}

\subsection{Reinforced concrete buildings}

Reinforced concrete moment resisting frames built between the 1970s to the 1990s are the predominant building type in the suburbs of L'Aquila city and areas surrounding the historical centres of affected towns in the Aterno Valley. These are typically 3-5 storey residential 
Fig. 10 Via Francia, Pettino.

Photograph of extended

perimeter column

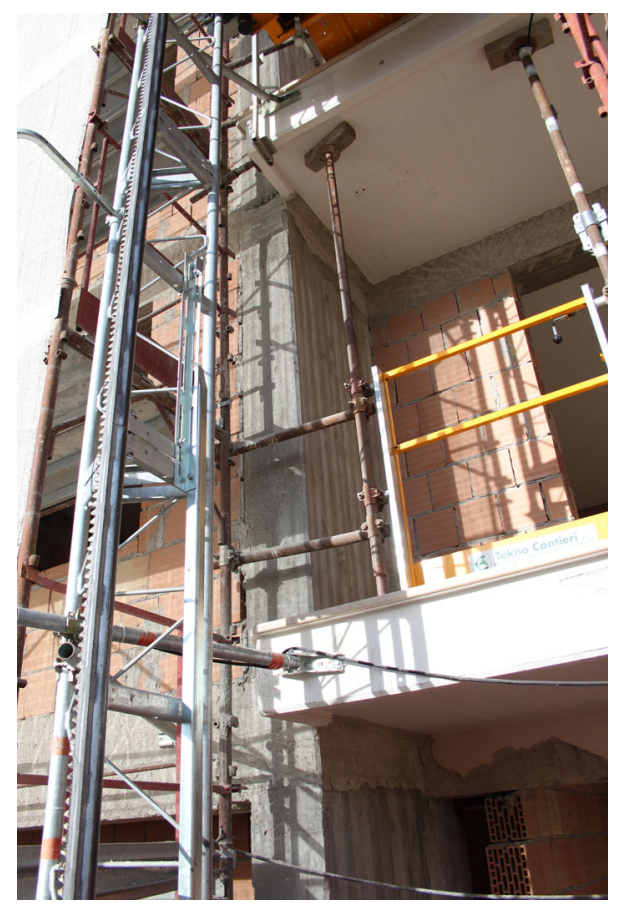

buildings and multi-storey (up to eight storeys) residential and office buildings. The moment resisting frames are infilled with hollow clay bricks, stronger clay bricks or concrete blocks. Floor and roof systems for these structures are composed either of reinforced concrete slabs or are of beam and block construction, where small RC precast beams with steel reinforcement in the bottom, support hollow clay blocks over which wire mesh and concrete screed is placed (Rossetto et al. 2009).

At the time of the EEFIT return mission many of these buildings were observed to be undergoing repair and strengthening, and a few were being demolished and replaced with new structures. Approval for works on these buildings would have been obtained from the "Filiera" process described in Sect. 4.1. Guidelines (Dolce and Manfredi 2010) for design of strengthening measures were produced by ReLUIS in 2009 and later updated in 2010 for application in L'Aquila, to meet the requirements of OPCM 3779 and NTC (2008) and Circular n. 617 (2009). These outline the main recommendations and design calculations for strengthening works used in the reconstruction. The three main types of strengthening intervention reported by ReLuis and observed in the field were the addition of fibre reinforced polymers (FRP), the increase of column dimensions and addition of shear walls.

Very similar repair and strengthening schemes were observed in the sites visited. In a typical retrofit observed in Via Francia, Pettino, perimeter columns were strengthened by increasing their depth from approximately $0.4-1.5 \mathrm{~m}$ over the full height of structure (see Fig. 10). Due to the cantilevering edge of the floor slabs, the face of the new column was flush with the slab edge. As the height to depth ratio of the column was approximately equal to two, the columns will behave as 'ductile walls'-i.e. walls where the performance is governed by bending. Photographs provided by site staff suggest that longitudinal and transverse reinforcement provided in the column extensions were at close centres, at or 


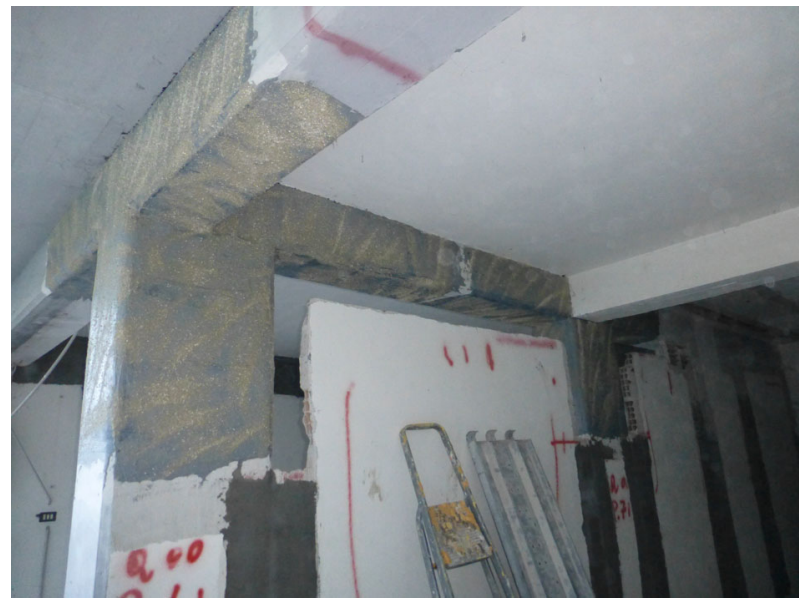

Fig. 11 Between Via Del Colle and Via di Strizzoli, Pettino. Beam/column joint strengthened with carbon fibre FRP. The image also shows that polypropylene mesh has been applied to connect the infill and columns

$<100 \mathrm{~mm}$, with longitudinal bars approximately $12-20 \mathrm{~mm}$ in diameter and transverse steel approximately $8-10 \mathrm{~mm}$ in diameter. Site staff informed the EEFIT team that the foundation ring and ground beams had also been improved as part of the works.

RC frame strengthening with FRP was almost universally adopted across retrofits and refurbishments visited, often in combination with the widening of columns or addition of shear walls. FRP was observed to be applied to beams, columns and beam-column connections to avoid brittle failure and improve ductility. FRP was also applied to beam-column connections to strengthen them against potential stresses imposed by infill panels (forming strut-like behavior in earthquakes). On apartment buildings, infill masonry panels were removed and replaced, with a polypropylene mesh fixed to beams and columns at edges to help restrain the masonry panel (Fig. 11). The aim of this modification was to prevent toppling of the panels, but not preclude damage.

In a very few cases steel frames were observed to have been applied or base-isolation introduced. For example, a new steel frame was observed to be applied to the concrete frame of a five storey block of apartments in L'Aquila (see Fig. 12). Three identical apartment buildings in Pettino were demolished and replaced with new structures incorporating seismic isolation at basement level (Fig. 13a). The five storey reinforced concrete frames incorporate garage space on the ground floor, are infilled with clay bricks and are approximately $28 \mathrm{~m} \times 14 \mathrm{~m}$ on plan. A grid of $6 \times 4$ concrete columns in the new basement support 24 "FIP Industriale" base isolators (Fig. 13b). The base isolators support a $400 \mathrm{~mm}$ thick RC slab and are in turn supported by $1.5 \mathrm{~m}$ high concrete columns that are a cruciform shape on plan and sit on a $600 \mathrm{~mm}$ thick raft foundation. It was noted on site that the cruciform section provides good biaxial stiffness while maintaining room for inspection and replacement of bearings if necessary. The basement retaining walls had been detailed to accommodate lateral displacement using a 'dog-leg' gutter detail, with also a vertical gap of approximately $15 \mathrm{~cm}$ at the slab edge.

\subsection{Masonry buildings (residential and historical)}

The masonry fabric typologies most frequently observed in the L'Aquila area are rubble stone, roughly squared stone blocks mixed with bricks, sometimes in regular courses, brick 


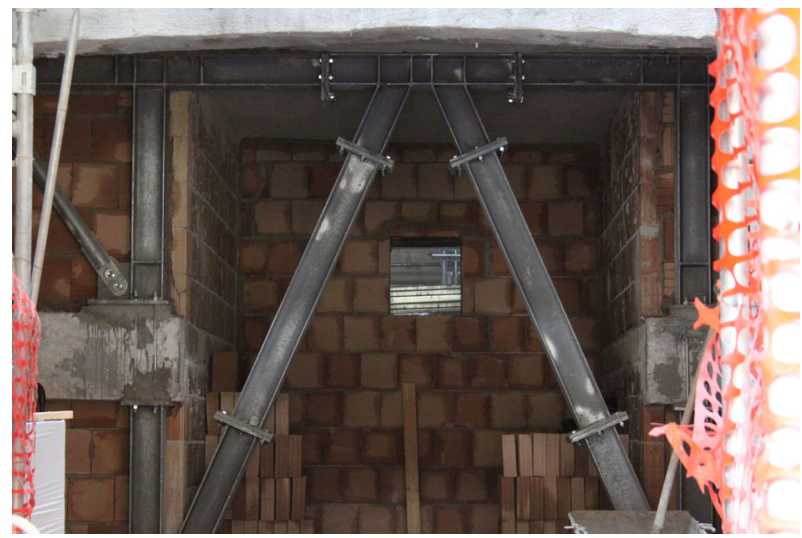

Fig. 12 Condominio Vico Picenze, L'Aquila. Retrofitted steelwork observed from the site boundary
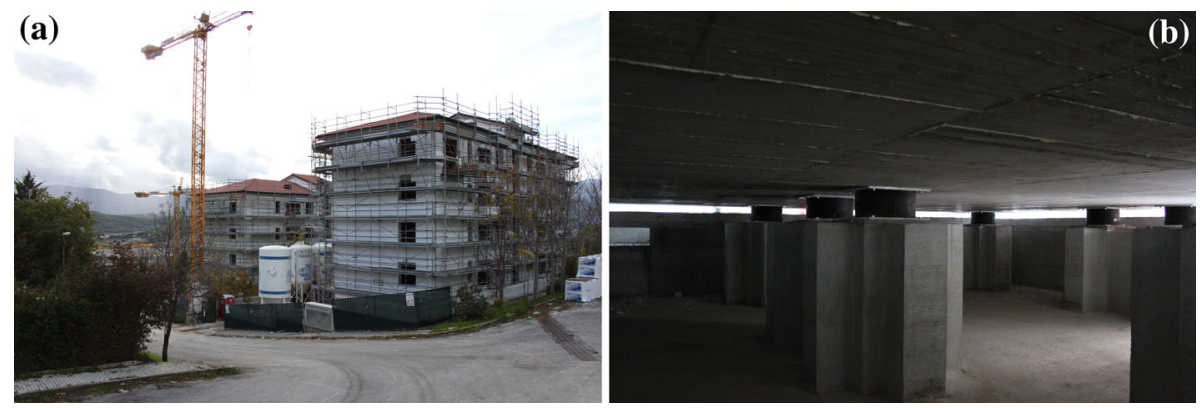

Fig. 13 Via Francia, Pettino. a Photo of the base-isolated buildings and $\mathbf{b}$ view of the base isolators in the basement

masonry, and dressed stone blocks. Walls in a few cases appear to be massive, but most commonly are formed by the so called "muratura a sacco", namely two wythes of dressed stones poorly connected, sometimes with a rubble infill. Mortar is mainly lime mortar. Large squared stone blocks are used for quoins. A typical intervention that was observed to be extensively used at the few sites which were undergoing restoration at the time of the EEFIT mission and that could be visited is fluid mortar injection grouting of all bearing walls. The aim of such an intervention is to improve the coherence and cohesion of existing walls by injecting them with fluid grout through a series of drilled holes regularly spaced on a $500 \mathrm{~mm}$ grid and proceeding from the bottom to the top, after having sealed and repointed the mortar joint. Although for material compatibility only lime-based grouts should be used, often epoxy additives or cement are included in the mix for faster setting. While such additive might improve the short term strength and cohesion of the masonry, they can create serious long term problems in terms of decay of the original materials due to different hydro-thermal behaviour and salt content.

Strengthening of floor to improve diaphragm action is recommended by the Linee Guida (Circolare n. 26/2010). This can be achieved by either nailing superimposed sets of floorboards at right angles or by adding a lightweight reinforced lime-based concrete screed above the existing set of floorboards. The reinforcement should be anchored in the perimeter masonry walls. Extensive tests campaign have been carried out at several institution in Italy in past years to devise the best technical details and performance improvement that 


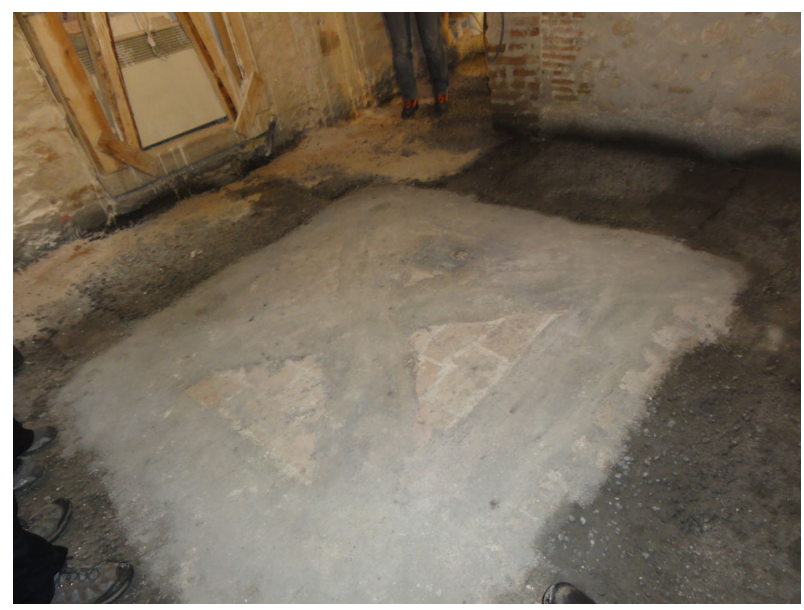

Fig. 14 reinforcement of a cross vault with strips of FRP laid at the extrados

can be obtained with such interventions (Riggio and Tomasi 2012). The joists and beams forming the floor structures should also be anchored to the walls by means of ties. A similar approach should be followed also for roof structures (Giuriani and Marini 2008). This type of intervention was traditionally extensively applied in the past and it can be observed that in cases where the ties have been well maintained and are regularly distributed on the wall, the damage is usually no greater than level B or A.

A common structural element of many buildings in L'Aquila is the brick vault. Brick vaults are present in lower floors of residential buildings as: a load bearing structure with a typically shallow cross-shaped arch profile, as a non-loadbearing false ceiling in upper floors (built in folio) and in most religious buildings as support to the roof structure. Post-earthquake surveys have revealed partial collapse and extensive damage of these structures. The Linee Guida (Circolare n. 26/2010) recommend either the use of traditional steel ties or specifically built spandrels at the extrados (Ferrario et al. 2009) while strengthening intervention with extradoxal reinforcement made of FRP strips (see Fig. 14) are tolerated with numerous provisos. While a body of research exist on the strength gain benefit of such interventions, most of the experimental research conducted to date focus on static concentrated loading conditions, or support movement, rather than dynamic performance (Modena et al. 2009). Durability and breathability are the major concerns.

The Linee Guida (Circolare n. 26/2010) recommend the use of ties and anchors to connect vaults and timber floors to walls, and walls to walls. A thorough review of traditional and modern solutions, their effectiveness, shortcomings and possible improvement by use of dissipative devices is included in D'Ayala and Paganoni (2013) and some surveyed examples are illustrated in Fig. 15. In the few sites undergoing repair or strengthening at the time of the return mission, there was no evidence of such strengthening devices being implemented.

In the only on-going project seen during the return mission, it was noticed that transversal reinforcement was applied to masonry walls by use of FRP bars, drilled through the thickness and then anchored by opening the threads as a star (Fig. 16). In the Guidelines issued in 2010 (Circolare n. 26/2010) it is stated that "the use of reinforced cores should be limited to cases where there is no other alternative due to the extreme alterations and disturbance produced vis 

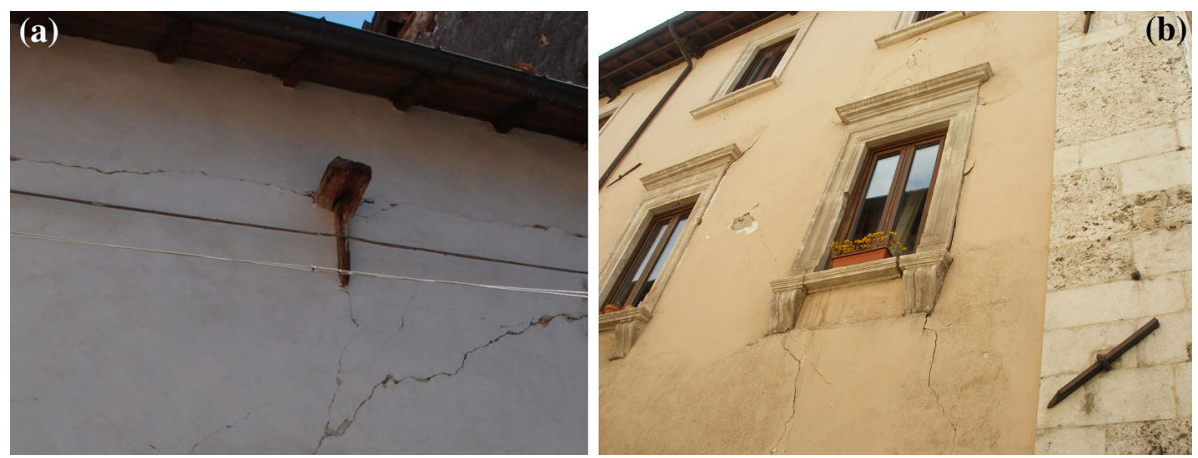

Fig. 15 Two examples of traditional reinforcement: a timber tie, b wrought iron cross tie inserted in a quoin

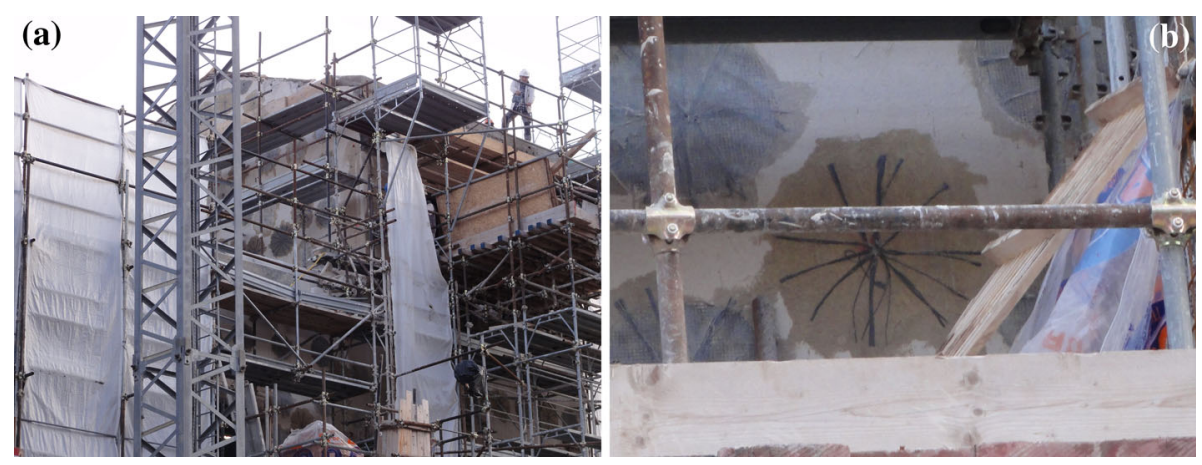

Fig. 16 Extensive use of reinforced coring with grouted injection with epoxy resins on the end wall of a five storey residential palace in the historic centre of L'Aquila

a vis [its] doubtful effectiveness, especially in the presence of walls with several wythes not well connected. In any case the durability of the strengthening element, whether of stainless steel, composite plastic materials or other material, should be ensured and the grouts used should be compatible with the original materials". Moreover it is advised that this type of intervention only has at best a local effect (Circolare n. 26/2010).

\section{Summary of observations from the L'Aquila EEFIT return mission}

Every earthquake improves our understanding of the response of buildings and infrastructure to the effects of ground shaking. This return mission has highlighted specific engineering lessons on the disaster management and reconstruction process that differ from those that can be obtained in the immediate aftermath of the event, and are here summarised:

- Post-disaster damage evaluation must meet different needs; those of safety assessment for human occupation, danger imposed to other buildings and urban access, and evaluation of damage in a way that is useful for the determination of repair, strengthening and economic cost of these. In addition, due to the large number of affected dwellings the assessment needs to be rapid and feasible to be carried out by non-specialised civil engineering 
professionals. The AeDES forms used in L'Aquila, seemed to fulfill these needs and form a useful tool for use in future damage assessments.

- In L'Aquila, partly due to the delay in re-building the historic centre, there has been an opportunity for detailed microzonation studies to be carried out that will quantify site effects and associated amplification of the ground motion for various hazard levels. The results of these studies have highlighted a consistent under-prediction of the spectral accelerations at short periods using the response spectra proposed by the Italian seismic regulation (NTC 2008). These results provide valuable inputs to the assessment and strengthening of buildings in the reconstruction process. The new Italian code (NTC 2008 and Circolare n. 617, 2009) already contains provision for using locally derived uniform hazard spectra.

- The widespread shoring of historic structures in the centre of L'Aquila represented a significant investment. Shoring was observed to be applied indiscriminately to almost all structures, whether lightly damaged or in a state ready for demolition. More accurate assessment of reserve capacity based on field observations may allow application of shoring to be more efficient following future earthquakes.

- The CASE project is seen to be an over-imposed and extremely expensive approach to transitional shelter that has led to social disruption, and in some ways hampered return to normal living and social interactions. There must be space for more local and site-related approaches, which guarantee the adequate level of participation and assure a high sense of ownership among the beneficiaries.

- With the reconstruction process dealing mainly with private buildings financed by public resources, the Government faced the need to write a new legislative framework for the reconstruction in Abruzzo. Inevitably, the process of setting up such a legislative framework took time, with new laws and regulations released progressively over the first two years after the earthquake. This fact, together with the new Italian Construction Code becoming compulsory after the events of April 6th about one year earlier than expected, led to confusion amongst professionals and technicians and resulted in a chaotic progress of the design process in the early stages. It is also noted that the deadlines for the design submission were strict: on one hand this helped to speed up the reconstruction process, on the other it resulted in additional confusion. In this context, the role of the "Filiera" as technical advisor for the Commissioner and the Government appears invaluable, to liaise with designers, assess the effectiveness of the proposed strengthening work and control their economic soundness.

- The financial policy put in place after the L'Aquila earthquake that allows seismic strengthening to be financed only for buildings in damage class " $E$ " will have direct consequences on the vulnerability of the building stock to future earthquakes. Only those buildings that were severely damaged are likely to be strengthened, hence those lightly damaged or undamaged by this earthquake will remain vulnerable to the next earthquake event.

- The use of Fibre Reinforced Polymer was commonly observed in the retrofit of existing reinforced concrete structures and masonry infill panels, but also in the case of historical masonry. The practical application of this technique varied from site to site visited. As such, clearer design guidance and wider understanding of the performance and limitations of this technique may improve the effectiveness of future retrofitting. This is especially true in the case of historical masonry, for which there is limited research on the use of this technique and its long term impact on the integrity of the masonry fabric. 


\section{Reflections on the value of return earthquake reconnaissance missions}

L'Aquila was the first ever earthquake return mission by EEFIT. Since this mission, EEFIT has conducted a return mission to the 2011 Tohoku Earthquake and tsunami, and EERI are launching return missions to areas affected by the 2004 Indian Ocean Tsunami in Sri Lanka and to the 2011 Christchurch earthquake in New Zealand. There is currently significant debate within international earthquake reconnaissance groups as to whether return missions should be conducted more regularly. It is the opinion of the Authors that return earthquake missions are important, and this section presents some reflections on the value that return missions can provide to the field of engineering in general, based on the EEFIT L'Aquila experience.

\subsection{Improving data on earthquake damage and loss}

Earthquake missions are invaluable for collecting data that can be used to decide what design and/or construction deficiencies led to inadequate structural performance. However, in order to collect this perishable data, earthquake missions are typically conducted soon after the earthquake, when buildings are commonly inaccessible internally as they have not yet been made safe. If timed correctly, return missions can help to better understand the structural systems affected as well as the deficiencies identified in the first mission. For example, in the L'Aquila mission the team was able to visit several buildings previously inaccessible, internally inspect some buildings, and observe structural details where concrete cover or plaster had been removed from damaged elements.

Immediately after an earthquake, the cost of damage and economic losses available are rough estimates. However, these estimates rarely get updated, or if they do, in the case of economic losses it is often difficult to discern direct from indirect losses. As seen in the L'Aquila mission, through interviews with local authorities it may be possible to obtain more detailed data both on the number of buildings affected and to which degree, but also on the costs involved in their reconstruction/strengthening. Such data, if made available, can be used to improve future loss estimates.

\subsection{Socio-economic implications of reconstruction and vulnerability reduction}

Return missions provide the chance to observe the reconstructions and strengthening process in action. As shown in this paper, they are also invaluable in allowing for an evaluation to be made of the strategy for reconstruction, the policies implemented for the finance and engineering approval of reconstruction works, and the impact that these have on the resilience of the earthquake affected sites.

Furthermore, it is likely that the earthquake has exposed local deficiencies in building practices or that completely new deficiencies have now emerged, and that the local construction industry may not have the required skills to remedy them or in many cases even be capable of implementing current best practice. For example, materials specified by codes may not be locally available and so not used (e.g. see Wilkinson et al. 2012), or in the L'Aquila case, close collaboration was required between engineers in ReLUIS and local engineers in order to get structural designs through the approval process. Understanding how this impacts on the construction industry is an important and poorly understood aspect on which longitudinal studies (i.e. studies observing the processes involved over long periods of time) can provide valuable insights.

In terms of response, housing shortages may necessitate the implementation of some form of transitional housing between providing basic shelter immediately after the event 
and permanent housing. Return missions can help build an evidence base of good and bad practice on the typologies of this housing, the urban and services planning of temporary housing sites and the housing policy implementation. Furthermore, they can help evaluate whether any social divides have been created, say by unequal distribution of aid and resources. In order to do so, it is important that the mission teams comprise experts capable of evaluating the adequacy of the transitional housing from an engineering, urban planning and a social standpoint, within the local context of the earthquake affected site.

\subsection{Scientific value}

The main reason for conducting earthquake reconnaissance missions is to gain valuable information that can help us to better understand deficiencies in current knowledge of earthquake risk. The best way of achieving this is to use the data in rigorous scientific studies to prove or disprove the suitability of current and proposed hazard or vulnerability models. In the case of the immediacy mission, this can prove difficult as the researcher must be either lucky that the earthquake provides the data that they require for their scientific purposes or opportunist - can modify their research to make best use of the data that has been obtained. Both these approaches have been successfully applied on numerous occasions and our continued improvement in seismic practice is testimony to this; however longitudinal studies can afford more time to make more controlled measurements and collection of data and provide opportunities for collaborations with local academics or practitioners. An example from the L'Aquila study is the availability of microzonation studies for better identification of the local seismic hazard.

\subsection{Testing data collection tools}

A returning mission is the ideal environment to perform a live test on any proposed damage or exposure data collection tools. First of all, the knowledge of the area acquired in previous deployments allows the field team to identify test areas with a varied distribution of building typologies. In this case, the same study area can be used to model several collection scenarios. Moreover, as was the case in the L'Aquila return mission, where the Global Earthquake Model (GEM) tools for exposure data collection were tested, the possibility to have developers and field team engineers working side by side provides a unique combination of expertise and deep insights in the functionalities and ergonomics of the tools. The collaboration is certainly favoured by the less stringent conditions of urgency that otherwise characterise a field deployment immediately following an earthquake. Lastly, the testing can also benefit from data already collected from previous missions for the validation process of the results.

\subsection{Mission planning and training benefit}

Immediacy missions are difficult and often potentially dangerous to conduct. Difficulties arise from the rapid deployment of mission members who must be gathered at extremely short notice and find time in their busy schedules for weeks or even months of absence from their normal duties. Each earthquake presents us with new and often dissimilar opportunities to learn how to better protect our communities from disasters and so members with different expertise need to be selected and different types of equipment must be collected with mission members being trained in their use. Earthquakes often occur in developing countries and their impact can lead to a reduction in the rule of law and good governance. Even in well-developed regions, there are still safety concerns. Immediacy missions may therefore not be adequate 
scenarios in which to provide training to team members with little experience of earthquake reconnaissance.

Return missions allow us to take a more considered approach in both the planning and operation of earthquake reconnaissance. They enable work commitments to be rescheduled, and local academics and authorities involved in the reconstruction to be contacted in advance. They allow for the training of mission members in reconnaissance, equipment operation and safe procedures before their deployment (e.g. 10 of the EEFIT L'Aquila Return Mission team had never been to an earthquake affected site). Moreover, they are a better environment to test new techniques and equipment that may help us gather data and information as well as gathering specific information that can be used in future research.

Overall, the Authors believe that return earthquake missions are invaluable as they foster an in-depth study of the recovery process, which helps to build an evidence base that can underpin research into realistic/successful strategies for future reconstruction and resilience building.

Acknowledgments EEFIT would like to thank the UK Institution of Structural Engineers and in particular Ms Berenice Chan for their continued support. The participation of T. Rossetto, D. D'Ayala, S. Kontoe, G. Elia, J. Han, E. Verrucci and V. Novelli in the EEFIT mission was funded by the Engineering and Physical Sciences Research Council (EPSRC), who are thanked for their support. The British Geological Survey, Risk Management Solutions, Atkins, ImageCat and Arup are thanked for sponsoring the participation of their employees. The ReLuis engineers in L'Aquila are thanked for the time spent explaining the authorization process for repair to building to the Team. EEFIT would also like to thank ing. Fabrizi (Comune de L'Aquila) and arch. De Vitis (Soprinitendenza ai Beni Culturali) for their time and kindness. The data provided by SED Spa with assistance from ing. Adolfo Paravano and Franco Colonna are gratefully acknowledged. Dott. Ing. Paravano (BDE) and Dott. Ing. Tursini (Ospedale San Salvatore) are also thanked for kindly making data available for statistical and research purposes.

Open Access This article is distributed under the terms of the Creative Commons Attribution License which permits any use, distribution, and reproduction in any medium, provided the original author(s) and the source are credited.

\section{References}

Alexander D (2010) The L'Aquila earthquake of 6 April 2009 and Italian government policy on disaster response. J Nat Resour Policy Res 2(4):325-342

Ambraseys N (1968) An engineering seismology study of the Skopje earthquake of 26 July 1963. Chap. 2. UNESCO Publ Paris 66:35-87

Amoroso S, Del Monaco F, Di Eusebio F, Monaco P, Taddei B, Tallini M, Totani F, Totani G (2010) Campagna di indagini geologiche, geotecniche e geofisiche per lo studio della risposta sismica locale della città dell'Aquila: la stratigrafia dei sondaggi giugno-agosto 2010. CERFIS - Centro di Ricerca e Formazione in Ingegneria Sismica, Università dell'Aquila, Pubblicazione CERFIS 1/10. L'Aquila, September 2010. 50 pp (in Italian)

Amoroso S, Marchetti D, Marchetti S, Monaco P, Totani F, Totani G (2011) Site characterization by seismic dilatometer (SDMT) in the area of L'Aquila. In: D’Ovidio G, Nakamura Y, Rovelli A, Valente G (eds) The dynamic interaction of soil and structure. Aracne editrice, Roma, pp 37-62

Baggio C, Bernardini A, Colozza R, Corazza L, Della Bella M, Di Pasquale G, Dolce M, Goretti A, Martinelli A, Orsini G, Papa F, Zuccaro G (2007) Field Manual for post-earthquake damage and safety assessment and short term countermeasures (AeDES). European Commission, Joint Research Centre, Institute for the Protection and Security of the Citizen, Luxembourg

Baker JW, Cornell CA (2006) Spectral shape, epsilon and record selection. Earthq Eng Struct Dyn 35(9):10771095

Calabrese R (2010) Abruzzo, ad Onna la consegna delle casette in legno. Edilportale News Article, available at: http://www.edilportale.com/news/2009/09/lavori-pubblici/abruzzo-ad-onna-la-consegna-del le-casette-in-legno_16389_11.html

Calvi GM (2010) L'Aquila earthquake 2009: reconstruction between temporary and definitive. New Zealand society for earthquake engineering 2010 conference proceedings, Paper no 1, 12 pp 
Calvi GM, Spaziante V (2009) Reconstruction between temporary and definitive: the CASE project. Progettazione Sismica 3:221-250

Chiodi G (2012) Relazione finale del Commissario Gianni Chiodi. Commissario delegato per la Ricostruzione, 29 October 2012, LAquila

Cimellaro GP (2013) Correlation in spectral accelerations for earthquakes in Europe. Earthq Eng Struct Dyn 42(4):623-633

Circolare n. 617 (2009) Istruzioni per l'applicazione delle "Nuove norme tecniche per le costruzioni" di cui al D.M. 14 gennaio 2008, Ministero delle Infrastrutture e dei. Trasporti, pubblicata sulla Gazzetta Ufficiale n. 47 of the 26 February 2009, suppl. Ordinario n. 27. 2 February 2009

Circolare n. 26/2010 (2010) Linee Guida per la valutazione e riduzione del rischio sismico del patrimonio culturale-allineamento alle nuove Norme tecniche per le costruzioni, Ministero per i Beni e le Attività Culturali, Prot. 10953 del 2 dicembre 2010

Comune di L'Aquila (2011) Il piano di ricostruzione dei centri storici di L'Aquila e frazioni, Relazione, December 2011

Commissario per la ricostruzione, Presidente della Regione Abruzzo, Ufficio Coordinamento Ricostruzione (2011) Quesiti sugli aggregati e sui consorzi-aggiornamento 13.5.2011. Available at: http://www. commissarioperlaricostruzione.it/layout/set/print/FAQ/

Consenza E, Manfredi G (2010) L'Aquila: il progetto C.A.S.E. IUSS Press, Pavia

D'Ayala D, Paganoni S (2013) Protocol for testing and design of dissipative anchor devices. Structures and Buildings (in print)

Dipartimento della Protezione Civile-DPC (2010a) Rapporto Conclusivo Emergenza. Protezione Civile Nazionale, Emergenza Terremoto Abruzzo, Auditorium Scuola Guardia di Finanza, 29 January 2010, L'Aquila

Dipartimento della Protezione Civile-DPC (2010b) Rapporto sintetico dell'attività della DI.COMA.C per l'avvio della fase di affiancamento alla struttura del commissario dellegato-Presidente della Regione Abruzzo (art.1 comma 4 dell'OPCM 3833 del 22/12/2009). 29 January 2010, L'Aquila

Dipartimento della Protezione Civile-DPC (2010c) Progetto C.A.S.E: è terminata la costruzione di tutti gli edifici. 28 February 2010, LAquila (accessed 7 December 2012) http://www.protezionecivile.gov.it/jcms/ it/view_new.wp?contentId=NEW795

Dipartimento della Protezione Civile-DPC (2010d) PC-Abruzzo: completato il passaggio di consegne. 1 March 2010 (Accessed 6 December 2012). http://www.protezionecivile.gov.it/jcms/it/view_new.wp? contentId=NEW802

Dipartimento della Protezione Civile_DPC (2010e) Dossier: MAP_-Moduli Abitative Provvisori. Accessed 7 December 2012. http://www.protezionecivile.gov.it/jcms/it/view_dossier.wp?contentId=DOS323

Dolce M, Manfredi G (2010) Linee guida per la riparazione e il rafforzamento di elementi strutturali, tamponature e Partizioni. Protezione Civile and ReLUIS, May 2010. Available at: http://www.reluis.it/doc/ pdf/Linee_guida1.pdf

Ferrario L, Marini A, Riva P, Giuriani E (2009) Traditional and innovative techniques for the seismic strengthening of barrel vaulted structures subjected to rocking of the abutments. Improving the Seismic Performance of Existing Buildings and Other Structures, pp 1329-1340

Giuriani E, Marini A (2008) Wooden roof box structure for the anti-seismic strengthening of historic buildings. Int J Archit Herit 2(3):226-246

Grimaz S (2011) Management of urban shoring during a seismic emergency: advances from the 2009 L'Aquila (Italy) earthquake experience. Bollettino di Geofisica Teorica ed Applicata 52(2):341-355

L'Aquila municipality data service (2012) Correspondence. Servizi Elaborazioni Dati (S.E.D.) Spa, Via Salaria Antica Est, 67100 L'Aquila

Mayne PW, Schneider JA (1999) Small and large-strain soil properties from seismic flat dilatometer test. In: Jamiolkowski Lancellotta R, Presti Lo (eds) Proceeding of pre-failure deformation characteristic s of Geomaterials. Balkema, Rotterdam

Modena C, Casarin F, DaPorto F, Garbin e, Mazzon N, Munari M, Panizza M, Valluzzi M (2009) Structural interventions on historical masonry buildings: review of eurocode 8 provisions. In: the light of the Italian experience. In: Cosenza e (ed) eurocode 8 Perspectives from the Italian Standpoint Workshop, (C) 2009 Doppiavoce. Napoli, Italy, pp 225-236

Modena C, Da Porto F, Casarin F, Munari M, Simonato E (2010) Cultural heritage buildings and the Abruzzo Earthquake: performance and post-earthquake actions. Adv Mater Res 133:3-17

MS-AQ Working Group (2010) Microzonazione sismica per la ricostruzione dell' area aquilana. 3 Vol. + CD rom. Regione Abruzzo-Dipartimento della Protezione Civile, L'Aquila (in Italian)

Musson RMW (2013) A history of British seismology. Bull Earthq Eng 11(3):715-861

NTC (2008) Norme Tecniche per le Costruzioni. DM 14 gennaio 2008, Gazzetta Ufficiale, n. 29 del 4 febbraio 2008, Supplemento Ordinario n. 30, Istituto Poligrafico e Zecca dello Stato, Roma (www.cslp.it) 
Pacor F, Ameri G, Bindi D, Luzi L, Massa M, Paolucci R, Smerzini C (2011) Characteristics of strong ground motions from the L'Aquila $(\mathrm{Mw}=6.3)$ earthquake and its strongest aftershocks. Bollettino di Geofisica Teorica ed Applicata 52(3):471-90

Riggio M, Tomasi R, Piazza M (2012) Refurbishment of a traditional timber floor with a reversible technique: the importance of the investigation campaign for the design and the control of the intervention. Int $\mathrm{J}$ Archit Herit 8(1):74-93

Rossetto T, Peiris N, Alarcon JE, So E, Sargeant S, Free M, Sword-Daniels V, Del Re D, Libberton C, Verrucci V, Sammonds P, Faure Walker J (2009) The L'Aquila (Italy) Earthquake of 6th April 2009: a preliminary field report by EEFIT. Available at: http://www.istructe.org/webtest/files/b8/ b8df351b-a28b-4375-9d5a-20afd9be569b.pdf

Rossetto T, Peiris N, Alarcon JE, So E, Sargeant S, Free M, Sword-Daniels V, Del Re D, Libberton C, Verrucci V, Sammonds P, Faure Walker J (2011) Field observations from the Aquila, Italy Earthquake of April 6, 2009. Bull Earthq Eng 9(1):11-37

Totani G, Monaco P, Marchetti S, Marchetti D (2009) $\mathrm{V}_{S}$ measurements by seismic dilatometer (SDMT) in non-penetrable soils. In: Hamza $M$ et al (eds) Proceedings of 17th international conference on soil mechanics and geotechnical engineering, vol 2. IOS Press, Alexandria, pp 977-980

Wilkinson SM, Alarcon JE, Mulyani R, Whittle J, Chian SC (2012) Observations of damage to buildings from $M_{W} 7.6$ Padang earthquake of 30 September 2009. Nat Hazards 63(2):521-547

\section{New regulations promulgated during the Abruzzo Emergency and Reconstruction}

Presidenza del Consiglio dei Ministri, O.P.C.M. n. 3767/2009, 13th May 2009

Presidenza del Consiglio dei Ministri, O.P.C.M. n. 3771/2009, 20th May 2009

Presidenza del Consiglio dei Ministri, O.P.C.M. n. 3779/2009, 6th June 2009

Presidenza del Consiglio dei Ministri, O.P.C.M. n. 3782/2009, 17th June 2009

Presidenza del Consiglio dei Ministri, O.P.C.M. n. 3790/2009, 9th July 2009

Presidenza del Consiglio dei Ministri, O.P.C.M. n. 3797/2009, 30 July 2009

Presidenza del Consiglio dei Ministri, O.P.C.M. n. 3813/2009, 29th September 2009

Presidenza del Consiglio dei Ministri, O.P.C.M. n. 3817/2009, 16th October 2009

Presidenza del Consiglio dei Ministri, O.P.C.M. n. 3820/2009, 12th November 2009

Presidenza del Consiglio dei Ministri, O.P.C.M. n. 3832/2009, 22nd December 2009

Presidenza del Consiglio dei Ministri, O.P.C.M. n. 3870/2010, 21st April 2010

Presidenza del Consiglio dei Ministri, O.P.C.M. n. 3917/2010, 30th December 2010

\section{Web Sources}

Commissario Per La Ricostruzione: www.commissarioperlaricostruzione.it. Accessed March 20, 2013

ReLuis www.reluis.it. Accessed 20 March 2013

Cineas. www.cineas.it. Accessed 20 March 2013

Fintecna. www.fintecna.it. Accessed 20 March 2013

Protezione Civile. www.protezionecivile.it. Accessed 20 March 2013 